\title{
TRABALHO E COMUNICAÇÃO: REFLEXÕES SOBRE UM CONCEITO DIALÉTICO DE COMPETÊNCIA
}

\author{
WERNER MARKERT
}

\begin{abstract}
RESUMO: A discussão atual sobre o conceito de competência demonstra ainda uma grande inconsistência sobre seus fundamentos teóricometodológicos. Para evitar que o conceito fosse unicamente uma contribuição tecnicista, que segue uma moda atual e tencione somente a conformação da subjetividade dos trabalhadores à nova ideologia progressista do capital, pretendemos desenvolver um conceito integral de competências, que reflete as relações complexas entre o mundo do trabalho e o mundo da vida, e se refere à discussão sobre o conceito de trabalho nas visões teóricas de Antunes, Marx e Habermas e estudos empíricos de Baethge, Rojas, Tanguy e Zarifian. O objetivo é mostrar, que nas perspectivas universais de trabalho e de comunicação identificam-se com as raízes do desenvolvimento universal da produção e da competência do sujeito.

Palavras-chave: Trabalho. Comunicação. Competência. Educação profissional.
\end{abstract}

\section{WORK AND COMMUNICATION: \\ REFLECTIONS ON A DIALECTICAL CONCEPT OF COMPETENCE}

ABSTRACT: The current discussion about the new concept of competence demonstrates a great theoretical and methodological incoherence. To avoid limiting this concept to a technical vision that follows a fashion and only studies how the workers' subjectivity conforms to the new, progressive ideology of capital, we intend to develop an integral concept of competence that reflects the complex relationships between the universes of work and life. We thus refer both to the discussion of the concept of work according to both Antunes, Marx and Habermas' theoretical standpoints and the empirical studies of Baethge, Rojas, Tanguy and Zarifian. Our intention is to show that, in the universal perspective of work and communication, they are linked

Professor visitante do Departamento de Educação da Universidade Federal do Rio Grande do Norte (UFRN).E-mail:wmarkert@hotmail.com 
to the roots of universal development of production and of the subject competence.

Key words: Work. Communication. Competence. Professional education.

\section{Introdução}

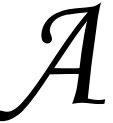

discussão internacional sobre o conceito de competência surgiu junto às mudanças do paradigma de produção nos anos oitenta. $\mathrm{Na}$ França, ${ }^{1}$ p. ex., teve suas origens em um discurso empresarial e foi ampliada, criticada, concretizada por economistas e sociólogos:

É uma noção bastante imprecisa e decorreu da necessidade de avaliar e classificar novos conhecimentos e novas habilidades geradas a partir das novas exigências de situações concretas de trabalho, associada, portanto, aos novos modelos de produção e gerenciamento, e substitutiva da noção de qualificação ancorada nos postos de trabalho e das classificações profissionais que lhes eram correspondentes. (Hirata, 1994, p. 132)

As "competências" de um profissional são representadas no "poder estruturante" que ele pode assumir no processo participativo das mudanças nas organizações:

Se a noção de competência tem uma longa história nos diferentes registros da língua, ela está há alguns anos muitas vezes associada à noção de "organização do trabalho qualificante" (...). É esse uso que iremos privilegiar aqui para submetê-lo à análise. (Tanguy, 1997, p. 168)

Pretendo, a partir deste entendimento, refletir sobre as mudanças no mundo do trabalho, que fortaleceram, na discussão sociológica internacional, a substituição das análises sobre qualificações em favor de um novo conceito de competência (Manfredi, 1998).

As duas perspectivas admitem que os processos sociais de modernização geram uma mudança de paradigma, ou até mesmo uma ampliação do conhecimento no trabalho, que teve seu reflexo na sociedade "taylorizada" com sua rígida divisão do planejamento e da execução do trabalho. Assim, devemos substituir o conceito tradicional de conhecimentos e de saberes pela visão de competência, que não deverá ter somente uma conotação funcionalista em relação às mudanças sociais e laborais, mas, por ser "essencialmente política", orientar-se-á pela capacidade subjetiva de poder intervir e transformar estruturas tradicionais no trabalho e na vida social (Machado, 1998). 
O debate atual sobre as novas competências no trabalho e na vida demonstra ainda uma grande incerteza sobre as suas fundamentações teórico-metodológicas e prático-pedagógicas, o que repercute diretamente sobre o entendimento de que seus objetivos venham a ser emancipatórios ou somente instrumentais. ${ }^{2}$

Essa questão implica a seguinte discussão: estas mudanças determinam apenas uma instrumentalização das novas qualificaçōes adquiridas no capitalismo tecnologicamente avançado, conformando a subjetividade dos trabalhadores ao novo nível de acumulação e modelando o homem laboral para ajustar sua consciência à nova ideologia progressista do capital, ou trata-se de uma mudança que avança tendencialmente para a superação das limitações do homem na produção capitalista? Neste sentido, nossa discussão será fundamentada numa abordagem histórico-crítica, baseada na análise das dimensões integrais (trabalho e comunicação) de um conceito dialético da formação do homem. ${ }^{3}$

Conseqüentemente, cabe-nos a tarefa de discutir a referência da noção trabalho para um conceito emancipatório de competência: a categoria trabalho poderia ser a única para o desenvolvimento deste conceito, ou precisamos de outras categorias, que estejam voltadas às múltiplas dimensóes do conceito de competência? Entendendo a noção de competência através de uma metodologia dialética, reconhecemos uma semelhança significativa com a concepção de politecnia, cujo objetivo principal é a superação social e subjetiva da divisão entre capacidades intelectuais e práticas do homem. Propomos, portanto, para a construção teórica do conceito de competência, a concentração da análise nas seguintes categorias, as quais devem manter entre si uma perspectiva dialética: trabalho e comunicação.

Analisamos neste estudo, inicialmente, as mudanças no sistema de trabalho, na produção e no serviço, em comparação com as mudanças no mundo de vida, para podermos aprofundar a base histórico-empírica das teses centrais sobre o conceito de competência. Abordamos, em seguida, as questóes teórico-metodológicas das categorias centrais e concluímos com reflexões sobre um conceito integral e crítico de competência, que reflete as relações das categorias com a visão da formação do sujeito em estruturas de trabalho que permitem a intervenção participativa de homens autônomos.

\section{Mudanças no mundo do trabalho}

A tese do surgimento de competências sócio-cooperativas e sóciocomunicativas, como conseqüência das mudanças estruturais no processo 
de reorganização produtiva (Hirata, 1994; Markert, 1998; Zarifian, 1999) e da individualização dos papéis sociais (Touraine, 1995; Baethge, 1994; Beck, 1995), destaca-se, na última década, nas análises acerca das mudanças no mundo do trabalho

Neste sentido, hoje, existem pesquisas empíricas na sociologia do trabalho que analisam as mudanças ocorridas nos processos de produção à luz dos interesses dos trabalhadores e seus sindicatos, objetivando conhecer melhor o sistema de "produção flexível". Na Alemanha, destacase nesta área o Instituto de Pesquisa Social de Göttingen. O diretor do Instituto, Martin Baethge, resumiu os novos paradigmas das competências para o mundo do trabalho do futuro num parecer para o Ministério da Educação e Pesquisa (BMBF).

Não há dúvida de que o processo de reestruturação produtiva é conseqüência da competição aguda nos mercados internacionais e das dificuldades de manter ou aumentar os lucros, objetivando atender os interesses dos acionistas. Para poder sobreviver na concorrência mundial, as empresas têm de agir competitivamente, dentro de um "quadrado mágico: elevada qualidade, orientação no cliente, inovação acelerada, preços acessíveis" (Baethge/Schiersmann, 1998, p. 21). A base da reestruturação encontra-se na necessidade de flexibilização organizacional da produção. Assim, os critério considerados nesta mudança são:

- Dinamização do processo de produção através de mecanismos de out e insourcing;

- descentralização da organização da empresa em unidades multifuncionais;

- cooperação transversal (em projetos temporários ou permanentes) entre empregados de áreas e qualificações/ocupações diferentes;

- dissolução de funções ocupacionais tradicionais por meio da integração de novos elementos nas tarefas;

- organização interna desierarquizada.

Ao se observar os fatores negativos, reconhece-se a tendência do outsourcing e da flexibilização dos contratos. A conseqüência destes mecanismos para os trabalhadores é a ameaça de demissões, e a conseqüência social reside no fato de que somente uma parte dos trabalhadores qualificados pode desfrutar das vantagens de qualificação e ocupação dentro do novo sistema de produção, as quais podemos definir como conceitos estruturalmente inovadores de trabalho em grupo. ${ }^{4}$ 
Baethge observou em sua pesquisa um fator importante: a extensa flexibilização causou grandes distorçōes no decorrer da produção de certas empresas, porque a crescente complexidade da cooperação entre profissionais de departamentos diferentes não exige somente um trabalhador formalmente flexível, mas com longa experiência ocupacional na empresa. Como também reconhece Machado:

(...) a criação dos CCQs (Círculos de controle de qualidade) marca o reconhecimento que os trabalhadores são os únicos capazes de resolver problemas desconhecidos pelos serviços funcionais e o reconhecimento de uma qualificação coletiva, ignorada por Taylor. (Machado, 1998, p. 37)

Esses pontos-chave definem os princípios gerais para o pessoal da fabricação e da montagem, pois eles não somente adaptam os conhecimentos técnicos das empresas reestruturadas, como também se tornam aptos para dispor de uma visão geral e de uma consciência crítica na definição de alternativas no trabalho, conforme as decisões individuais e grupais, que inclui a rotatividade igualitária de todos os participantes como acontece, por exemplo, na "ilha de produção".

Para o desenvolvimento dessas capacidades na ilha de produção foram aplicadas as seguintes medidas:

- Os participantes da ilha de produção obtêm um espaço de tempo transparente, no qual executam tarefas para a fabricação de um certo produto. Eles podem desenvolver de forma autônoma todas as atividades necessárias para o término do trabalho, com um tempo determinado pelo fluxo da produção para a entrega do produto. O grupo adquire experiência quanto à capacidade de desenvolver as qualificações práticas, sobre a obtenção de informações necessárias - das áreas anteriores e posteriores -, sobre o material a ser adquirido e quanto ao controle de qualidade. A divisão das tarefas acontece dentro do grupo em conjunto. A totalidade do grupo identifica as deficiências ainda existentes e pode definir, por exemplo, um plano de qualificação para cada um em relação às ações práticas;

- para poder realizar estas tarefas o grupo precisa anteriormente adquirir uma visão integral sobre a coerência do processo da produção. É necessário, neste momento, o apoio dos dirigentes da empresa responsáveis pelo processo de reorganização, no sentido de oferecer todas as informações solicitadas pelo grupo; 
- para o funcionamento da ilha de produção é indispensável a possibilidade de comunicação entre os membros do grupo e com as áreas anteriores e posteriores;

- a meta principal da ilha de produção é uma maior flexibilidade da organização para reagir mais rapidamente e com maior competência às diferentes demandas dos clientes, o que não é viável com a estrutura tradicional de divisão do trabalho. Neste sentido, combina-se uma maior competência do pessoal com a rentabilidade do processo de produção. Tarefas que Baethge caracterizou no seu "quadro mágico".

No trabalho em grupo orientado neste conceito, cresce a tendência de integração contínua dos conhecimentos técnico-profissionais, a capacidade de cooperação interdepartamental com profissões diferentes - superando hierarquias tradicionais e a antiga ocupação fragmentada e desqualificada.

Para Baethge, os "efeitos da primeira ordem "são aqueles que partem das tendências globais e exigem mudanças nas empresas e nos empregados, que podem ser descritas na dimensão das competências comunicativas ampliadas.

Essas competências superam a dimensão da sensibilidade social e tencionam a ligação entre competências técnicas e comunicativas. (...) Em comparação com as condições anteriores da produção taylorista, as competências comunicativas ampliadas encontram-se, hoje, no contexto do processo de produção, no qual podem ser apropriadas, visto que são vinculadas às novas constelações e situações de trabalho. (Bathge \& Schiersmann, 1998, p. 24)

Essas mesmas tendências podem ser identificadas no setor de serviços no âmbito mundial. Com a complexificação da produção, através da informatização, surge um tipo de "servidor produtivo" que deve ser capaz de observar as mudanças técnicas e organizacionais, conhecer o processo produtivo e a organização do trabalho, para que possa intervir rápido e efetivamente em casos da necessidade de interferências. Este servidor deve, ao mesmo tempo, comunicar-se com os trabalhadores envolvidos no processo, buscando as causas destes problemas para que o grupo de trabalho seja capaz de resolvê-los autonomamente. A contratação deste "servidor-produtivo" está crescendo continuamente, substituindo a mão-de-obra tradicional. "Para o servidor-produtivo, o trabalho tornase sempre mais reflexivo e transforma-se em linguagem, implicando na manipulação de signos, símbolos, e códigos" (Paiva, 1999, p. 102). Para este profissional, a capacidade de comunicação torna-se central tanto quanto o domínio do contexto no qual o conhecimento se aplica. 
A conseqüência destas mudanças para o sistema de formação profissional na Alemanha foi a reformulação integral dos currículos nas profissões do setor metal-mecânico, nos anos oitenta, e a criação de novas profissóes que integram competências técnicas e sociais, em combinação com conhecimentos de informática, nos anos noventa (Markert, 2000a).

O trabalhador qualificado na Alemanha dispõe hoje, em princípio, igualmente de competências técnicas e comunicativas, adaptando-se aos objetivos pedagógicos centrais do novo currículo no setor metal-mecânico (1987), que integra as competências técnicas, metodológicas e sociais, definidas nacionalmente com o apoio e pressão política do sindicato do setor.

Para Baethge é importante que a educação profissional do futuro relacione melhor o processo de aprendizagem profissional com as estruturas qualificantes dos conceitos estruturalmente inovadores de trabalho em grupo, que, na Alemanha, são desenvolvidas em projetos pedagógicos inovadores como a oficina de aprendizagem e as ilhas de aprendizagem (Markert, 1994 e 2000b) e na política integral de formação profissional dos trabalhadores e de servidores. Assim, poderia se evitar a segmentação social entre os "ganhadores" da reestruturação produtiva e os "perdedores" do processo de outsourcing nacional e internacionalmente. Nesta direção, a definição de uma política educacional integral passa a ser exigência para os sindicatos mundiais.

Zarifian discute as mudanças nas novas competências profissionais na mesma perspectiva. $\mathrm{Na}$ sua análise sobre as mudanças no trabalho, ele enfatiza a necessidade de combinar futuramente as áreas de produção e de serviço. O profissional de futuro precisa de um conhecimento integral da totalidade da produção, das unidades da empresa até o atendimento ao cliente. $\mathrm{O}$ trabalho tem que ser organizado em equipes que interagem em redes e tenham maior autonomia que na produção taylorista. As competências requeridas neste processo implicam um conceito transversal da integração dos conhecimentos (saberes técnico-metodológico) e da comunicação (relações intersubjetivas):

Comunicar es compreender al outro y compartir com él referentes, móviles y objetivos parcialmente comunes. Esto es muy visible em la vida profesional: las necesidades de comunicación (entre individuos, entre diferentes oficios o atividades, con los usários etc.) son enormes y multiformes. (Zarifian, 1999, p. 45 e ss.)

As tarefas a serem conectadas no futuro têm sua orientação na totalidade das atividades requeridas numa organização, por exemplo, 
em uma empresa de informática precisa-se de uma cooperação e comunicação contínuas entre vendedores, técnicos e prestadores de serviço em redes permanentes. As profissões não desaparecem, mas serão integradas numa visão integral da ocupação, exigindo competências transversais por parte de todos os assalariados. ${ }^{6}$

Essas mudanças implicam argumentos para superar o conceito tradicional de qualificações e saberes e fortalecem as discussões sobre um novo conceito de competência na educação geral e profissional. ${ }^{7}$

Resumimos as mudanças no mundo do trabalho, que apontam os objetivos para as competências do futuro:

1. As mudanças no mundo do trabalho exigem não apenas uma maior qualificação dos trabalhadores e servidores, mas também uma nova dimensão do conteúdo de suas capacidades, orientada no entendimento do processo integral da produção, nas competências integrais e universais;

2. as futuras exigências de qualificação para o trabalho são cada vez menos prognosticáveis. O objetivo de uma formação profissional para o futuro não deve ser orientado na aquisição de determinadas habilidades, mas sim na "capacidade de transferir conhecimentos para novas situações complexas" (Markert, 2000a), de desenvolver competências técnico-metodológicas transversais;

3. as mudanças sócio-culturais levaram a uma crescente mudança nas relações pessoais em nível mundial, principalmente para a geração mais jovem, cujas orientaçôes individuais entravam constantemente em conflito com os papéis sociais tradicionais na família, escola e no trabalho. ${ }^{8}$ Essas mudanças de uma "crescente subjetivação normativa" (Baethge) das aspirações dos jovens se direcionam às instituições escolares e profissionais para poder aplicar as competências sócio-comunicativas e subjetivas;

4. para evitar que o conceito de competência seja restrito a um entendimento somente funcionalista, destaca-se a necessidade de poder transgredir e transformar organizações e ocupações tradicionais resistentes ao assumir um "poder estruturante" (Tanguy) e uma "presença no mundo" (Freire) em direção a competências histórico-politicas transformadoras. 
2. Trabalho e comunicação: categorias principais para um conceito dialético de competência

\subsection{Sobre um conceito dialético ou ontológico de trabalho}

Começamos com a reflexão sobre a relevância da noção trabalho para um conceito dialético de competência. Em uma "perspectiva ontológica" do trabalho, Antunes refere-se literalmente ao pensamento de Georg Lukács:

Somente o trabalho tem na sua natureza ontológica um caráter claramente transitório. (...) Todas as determinações que, conforme veremos, estão presentes na essência do que é novo no ser social estão contidas in nuce no trabalho. $\mathrm{O}$ trabalho pode ser visto como um fenômeno originário, como modelo, protoforma do ser social. ${ }^{9}$

O trabalho, para Antunes, "é, portanto, resultado de um pôr teleológico que (previamente) o ser social tem ideado em sua consciência, fenômeno este que não está essencialmente presente no ser biológico dos animais" (Antunes, 1999, p. 136). Sendo o trabalho a categoria originária, "os nexos entre causalidade e teleologia se desenvolvem de modo substancialmente novo" (idem, p. 145). Neste sentido, Lukács (1979)

fala em posições teleológicas primárias, que remetem diretamente ao trabalho e à interação com a natureza, e em posições teleológicas secundárias (como a arte, a literatura, a filosofia etc.) mais complexificadas e desenvolvidas que as anteriores, porque supõem a interação entre seres sociais, como práxis interativa e intersubjetiva, mas se constituem como complexos que ocorrem a partir do trabalho em sua forma primária. (Ibid., p. 146)

Voltamos, em seguida, para poder discutir essa tese de Antunes sobre a obra de Marx. Este último analisa, nos "Manuscritos", a "essência humana" como algo próprio no interior do homem e caracteriza "o desenvolvimento dos cinco sentidos" como uma tarefa da humanidade e consequiência da sua história: o homem é um ser ativo, produtivo e sensivel, que

apropria seu ser multiforme de forma global, isto é, como homem integral. Todas as suas relações humanas com o mundo (ver, ouvir, cheirar, sentir, desejar, amar), em resumo, todos os órgãos da sua individualidade, como os órgãos que são diretamente comunal, são, em sua ação objetiva, (...) a apropriação deste objeto, a apropriação da realidade humana. (Marx, 1983, p. 120)

O ser humano vive para "iluminar sua riqueza interior" (idem). O homem apropria o mundo objetivo com a finalidade de apropriar sua 
própria "essência", sua riqueza interior e, por estas razões, ele luta (continua e conseqüentemente) contra sua repressão. Finalmente, na superação da propriedade privada, "os sentidos e os espíritos dos outros homens tornaram-se sua própria apropriação. Logo, além desses órgãos diretos, são constituídos órgãos sociais sob a forma da sociedade" (ibid., p. 121). Para Marx, o homem forma seus próprios sentidos, sua sensibilidade, e suas relações sociais num processo dialético: na interação com a natureza (no trabalho) e com o outro homem (na comunicação), num processo integral e universal.

Deve-se perguntar como uma teoria que se centraliza exclusivamente na ontologia e na teleologia do trabalho poderia implicar como telos a felicidade e o amor na humanidade, sem se referir às categorias que refletem o surgimento destes valores na cultura humana. Certamente, trabalho em si não produz a humanização da sensibilidade humana, mas o homem constitui as formas da sociedade. Pergunta-se se a visão do sujeito integral, omnilateral, somente pode ser imaginada em uma categoria como o trabalho, que analisa a relação do homem com a natureza, mas não trata especificamente da relação do homem com o outro homem. Este trabalho é eternamente vinculado à necessidade, à organização instrumental da cooperação dos homens, embora seja ao mesmo tempo, para os homens associados no capitalismo, a causa social da sua submissão à produção alienante: o "reino" do capital. Ainda sobre esta análise, podemos recorrer a Marx:

É só por intermédio da riqueza objetivamente desenvolvida do ser humano que a riqueza da sensibilidade humana (um ouvido musical, um olho sensível à beleza das formas, em suma, sentidos capazes de satisfação humana e que se confirmam como faculdades humanas) é cultivada ou criada. (Ibid., p. 122)

Marx, ao pretender definir uma "essência humana", que aparentemente é distinta do mundo dos objetos, reconhece uma dialética entre esta "essência" e os objetos. A superação desta dualidade acontece exclusivamente na capacidade do homem concreto, expressa em sua ação prática, como uma "verdadeira tarefa vital". Mas o desenvolvimento do mundo ainda não

foi até aqui concebido com relação à natureza humana, mas, só sob um ponto de vista utilitário superficial, desde que na situação de alienação só era viável conceber faculdades humanas sob a forma da existência humana em geral, abstrata (...), como política, arte, literatura etc. (Idem)

A visão de uma vida verdadeiramente humana forma-se - ainda no mundo alienado - na imaginação do homem, nas expressões humanas 
imateriais, na contemplação da beleza da arte, por enquanto nas suas formas espirituais. ${ }^{12}$

Ao resumir as reflexões sobre a fundamentação teórica da categoria trabalho, propomos demonstrar que, ao reconhecê-la em seu caráter dialético, seria difícil, senão contrário às intenções de Marx, identificar uma implicação ontológica e teleológica da sua teoria, que finalmente terminasse numa re-hegelianização da sua obra. $\mathrm{O}$ trabalho produz riqueza e pobreza, o progresso das forças produtivas e a mais-valia, mas somente forma as relações sociais da essência humana, os sentidos do homem. Ele é um ser genérico, "conseqüentemente livre", que apropria sua própria subjetividade num processo auto-determinado ${ }^{13}$ e, ao mesmo tempo, adapta-se vitalmente, técnica e sensivelmente, ao mundo objetivo: sendo um processo dialético e conflituoso entre as exigências da civilização e os valores humanos assimilados no processo cultural do gênero.

Finalmente, tendo em vista o conceito de "alienação" em Marx, percebe-se que ele está (inter) ligado ao reconhecimento pelo homem, mesmo no capitalismo, da essência da sua humanidade: a sensibilidade, a beleza, o amor, o sentido humano, dimensões que no processo de formação do homem não aparecem explicitamente na categoria trabalho (Habermas, 2000).

Nossas considerações sobre um conceito de competências, que tem sua base em uma teoria dialética, incluem a definição fundamental de Marx sobre o conceito dialético de sujeito na VI Tese sobre Feuerbach: A essência humana não é algo abstrato, imanente ao individuo singular. Em sua realidade é o conjunto das relaçôes sociais.

Para Habermas, essa determinação é, à primeira vista, uma crítica radical ao "individualismo metódico das ciências sociais burguesas" (1990, p. 114), mas ela deixa em aberto um entendimento lúcido da essência humana: "Por isso, devemos definir com maior precisão o que entendemos por 'essência humana" (idem, p. 114 e ss.).

Ao analisar a história do desenvolvimento da humanidade e dos indivíduos, reconhecemos que apesar do processo de produção de bens ser importante para a formação do homem, são igualmente relevantes as formas de reprodução das condições humanas, que determinam o processo das inter-relações entre homem e natureza, prática e conscientemente. Nestas relações, as interações e comunicações humanas simbólicas e lingüísticas assumem um valor igual aos processos produtivos: "trabalho e linguagem são anteriores ao homem e à sociedade" (idem, p. 118) e formam, contudo, igualmente a essência humana. 
Voltando a Marx, pode-se constatar que em toda a sua obra o homem aparece sempre como um sujeito livre, que traz em si as potencialidades de auto-desenvolvimento:

(...) o homem é um ente-espécie não apenas no sentido de que ele faz da comunidade (sua própria, assim como as de outras coisas) seu objeto, tanto prática quanto teoricamente, mas também (...) no sentido de tratar-se a si mesmo como a espécie vivente, atual, como um ser universal e conseqüentemente livre. (...) A universalidade do homem aparece na prática, na universalidade que faz da natureza inteira o seu corpo orgânico. (Marx, 1974, p. 99)

Desta maneira, o "materialista" Marx desenvolve sua metodologia própria, a dialética viva entre objeto e sujeito, a conciliação entre materialismo histórico e idealismo filosófico, referindo-se significativamente à teoria de Kant: o homem é essencialmente livre.

O homem não é um mero espelho ou fator das condições sociais. Sua vida não é independente do sistema de trabalho, mas ele dispõe de cinco sentidos a serem desenvolvidos, ele é capaz de

apreciar o mais belo espetáculo: Assim, a objetivação da essência humana, tanto teórica quanto praticamente, é necessária para "humanizar" os sentidos humanos, e também para criar os "sentidos" humanos correspondentes a toda riqueza do ser humano e natural. (Ibid., p. 129)

Todavia, estes sentidos reconhecem sua idealidade nas formas belas da arte e nas interações humanas naturais e, certamente, não nas formas do trabalho alienado.

Mais adiante, Marx apresenta uma perspectiva plenamente habermasiana, quando caracteriza as relaçōes verdadeiramente humanas entre homem e mulher: "A relação imediata, natural e necessária do ser humano como ser humano é também a relação do homem com a mulher (...). Dessa relação, pode-se estimar todo o nível da evolução do homem" (Marx, 1974, p 122). Assim, Marx entende "o conjunto das relações sociais" na dialética entre a relação humana mais natural, uma interação intersubjetiva incondicionalmente livre, e no nível histórico-social da humanidade, que não poderia ser uma sociedade regida pelos valores de trabalho alienado. Nos termos de Habermas, podemos reconhecer "homologias" entre "as sociedades modernas (universalistas) que devem formar para si uma identidade coletiva compatível, em ampla medida, com estruturas universalistas do Eu", que formam sujeitos social, moral e politicamente livres (Habermas, 1990, p. 29). 
A intenção de Habermas não é uma revisão total da teoria do materialismo histórico em Marx, mas ele tenciona a "reconstrução" desta teoria,

(...) a fim de melhor atingir a meta que ela própria se fixou: esse é o modo normal (quero dizer: normal também para os marxistas) de se comportar diante de uma teoria que, sob diversos aspectos, carece de revisão, mas cujo potencial de estímulo não chegou ainda a se esgotar. (Habermas, 1990, p. 11)

Aquilo que na obra de Marx ainda é significativamente importante em relação às teorias sociais modernas, como a teoria de sistemas, o funcionalismo americano, o estruturalismo francês e o pós-modernismo, é a visão dialética na interpretação do desenvolvimento do mundo produtivo e da humanidade:

Por essa razão, considero a decisão em favor do critério histórico-materialista do progresso, uma decisão não arbitrária: o desenvolvimento das forças produtivas, em conexão com a maturidade das formas de integração social, significa progresso na capacidade de aprendizagem em ambas as dimensões: no conhecimento objetivante e na consciência prático-moral. (Idem, p. 158)

Vejo, a partir da análise das obras de Marx e Habermas, as categorias centrais do conceito integral de competências: a competência técnica (trabalho), voltada para o domínio do processo de trabalho, e a competência comunicativa, direcionada para as relações humanas sem restriçôes, que "são incompatíveis com as estruturas de classe" (Habermas, 1990, p. 38).

Nesta visão das relações das forças produtivas com as "formas de intercâmbio" entre os homens, podemos identificar semelhanças entre os autores supracitados:

As condições sob as quais os indivíduos mantêm intercâmbio entre si, enquanto a contradição nos aparece, são condiçōes inerentes à sua individualidade e não algo externo a eles; condições nas quais estes determinados indivíduos, existentes sob determinadas relaçóes, podem produzir sua vida material e tudo o que ela se relaciona; são, portanto, as condições de sua auto-atividade, produzidas por esta auto-atividade. (...) Essas diferentes condições, que surgem primeiro como condições da auto-atividade e, mais tarde, como entraves a ela, formam ao longo de todo o desenvolvimento histórico, uma série concatenada de formas de intercâmbio, cuja concatenação consiste em que a forma anterior de intercâmbio, transformada num entrave, é substituída por outra nova que corresponde às forças produtivas mais desenvolvidas e, por isso mesmo, ao modo avançado da auto-atividade dos indivíduos. (Marx, 1991, p. 112) 
Ao interpretar a teoria de Marx, Habermas expressa que, na dinâmica do capitalismo, é imanente que o indivíduo parcial da sociedade de classe tradicional encontre perspectivas e possibilidades de sua emancipação junto com a crescente "liberação" de modos de vida na "sociedade civil", possibilitando-lhe uma independência cultural relativa em relação à esfera da produção. Nestas condições sócio-culturais, os indivíduos associados encontram oportunidades para formar forças pessoais de resistência às repressões normativas tradicionais e ensaiar entendimentos e interações igualitárias. Com o crescimento de espaços vitais dos indivíduos, que não estão tão diretamente submissos às estruturas produtivas, eles podem experimentar interações solidárias e formar suas identidades auto-conscientes, autônoma e coletivamente. Assim, para Manacorda, identificamos a liberação humana numa nova relação entre trabalho e não-trabalho: "Trabalho omnilateral e nãotrabalho igualmente omnilateral como desenvolvimento das potências da mente, do cérebro humano: é esta a manifestação do homem" (Manacorda, 1999, p. 84). ${ }^{14}$

É desta forma que compreendo as passagens de $O$ Capital nas quais Marx trata das potencialidades progressivas da "grande indústria" no processo de formação do "indivíduo totalmente desenvolvido". A formação do "homem integral" precisa do progresso do capitalismo, ${ }^{15}$ mas o capitalismo só pode ser superado pela associação de homens autoconscientes, capazes de interagirem e comunicarem-se livremente.

\section{2. "Trabalho qualificante" e "Zona de Inovação": estruturas organizacionais básicas para o desenvolvimento de competências}

Encontramos, finalmente, na relação dialética entre o Materialismo Histórico de Marx e a teoria da Ação Comunicativa de Habermas um conceito essencial para o entendimento da formação social e individual do homem. Habermas vincula esta ação, na sua idealidade, às implicaçōes emancipatórias das relações comunicativas, que possam gerar interaçôes individuais não submissas à lógica instrumental e ao poder social. Esta potencialidade imanente das interaçôes intersubjetivas verdadeiramente humanas permite "a intersubjetividade na qual um Eu pode identificar-se com o outro Eu, sem abandonar a não identidade entre ele e seu outro, estabelece-se também na linguagem e no trabalho (...)." Nesta relação "é possível uma interação à maneira dos sujeitos: e esse oposto é um oponente e não um objeto" (Habermas, 1987, p. 36). Em termos da dialética, o sujeito age e interage num processo de mediação dos dois momentos, "como processo de exteriorização 
(objetivação) e apropriação" (idem). Neste processo, o "outro" interage como um "oponente", sendo um Eu com uma identidade própria, mas não como objeto oposto. $\mathrm{O}$ conceito da interação/comunicação ideal reflete a possibilidade de reconciliação argumentativa entre os homens e supera as relações alienadas incorporadas no poder, na concorrência ou na racionalidade instrumental (coisificada) no capitalismo.

$\mathrm{Na}$ análise social atual, concluímos que as estruturas sociais e técnicooperacionais da organização do trabalho em sistemas de produção participativos, como o trabalho em grupo, determinam a necessidade e oferecem a potencialidade de adquirir competências universalistas na aprendizagem técnica e comunicativa, no sentido da dominação intelectual e prática (integralmente) da organização do trabalho (Markert, 2000a; Zarifian, 1999). Mas, como se sabe, esta potencialidade entra no capitalismo ainda em conflito com sua meta principal, ou seja, a produção de mais-valia.

Partindo das análises de Hirata e Tanguy, reconhecemos que o conceito de competência tem sua base nas estruturas do "trabalho qualificante". ${ }^{16}$ Zarifian salienta três dimensôes centrais:

- Competências participativas, relativas à capacidade dos assalariados de conhecer a função integral de uma organização; de saber como ela funciona; da intervenção no seu contexto; na participação da redefinição das suas estruturas.

- Competências transversais, relativas à cooperação em equipes e em redes de diferentes setores e implicam a compreensão do processo integral da produção ou do serviço.

- Competências sociais, que integram os campos: autonomia, responsabilidade e comunicação social nas profissóes futuras.

À luz da reflexão teórica das categorias trabalho e comunicação como base de um conceito crítico de competência, aquela determinação tal como posta por Zarifian corre o risco de orientar-se por uma perspectiva funcionalista das mudanças na produção e no serviço, destacando a adaptação dos novos modelos organizacionais do capitalismo "progressista" pelos assalariados. Na sua análise, falta a reflexão da relação das categorias em sua essência histórico-crítica, tanto em Marx quanto em Habermas. Seu entendimento da "autonomia" e das "competências sociais" está relacionado ao contexto da reorganização empresarial e não contém as dimensões da transgressão e transformação de estruturas fabris e de serviço, que estão em mudança, mas ainda funcionam dentro da lógica da produção da mais-valia. 
Uma proposta, que pretende implicar à compreensão integral do trabalho (ação produtiva) a perspectiva de ação comunicativa, encontra-se na definição da "zona de inovação" (Rojas, 1999). Partindo da necessidade futura de estruturas de "trabalho qualificante", ele vincula o "saber operário" não somente às mudanças funcionais na produção, mas à "transacción e interación entre el sujeto y sua experiência y el método de análisis reflexivo destinado a desorrollar competências en la acción. El aprendizaje es entonces una participación conflitiva en una 'comunidad de práticas"' (Rojas, 1999, p. 20). A reconstrução do saber operário não pode ser vinculada somente à racionalidade restrita da empresa, mas primeiramente a uma organização do trabalho como "zona de innovación" (idem, 21). ${ }^{17}$

Sem poder, neste momento, entrar em uma apresentação e discussão mais aprofundadas das idéias de Rojas, identifico no seu conceito a intenção de definir as estruturas do "trabalho qualificante" como contexto organizacional, no qual os atores coletivos conseguem interagir em condiçôes participativas e comunicativas sem restriçôes. A "zona de innovación" não se realiza funcionalmente como adequação das novas competências operárias às mudanças técnicas, mas sua implantação provoca, necessariamente, um processo conflituoso.

Sin embargo, la reflexión colectiva emprendida hará surgir el conflicto, inherente al processo de producción, entre mandos e operarios, de modo que su prosecución requirerá uma estratégia de negociaciones y compromissos em torno a nuevas reglas de acción, capaces de satisfazer las diferencias surgidas. (...) el campo de la negociación razonable no se restringe a los hechos e cosas instrumentalizables, como siempre, sino que incluye argumentos también razoables para apreciar la correción en el cumplimento de las normas del grupo y para pronunciarse sobre la autenticidad de los valores que esgrimen autonomamente los sujetos involucrados. (idem, p. 24)

A forma da aquisiçãao dos saberes é o método da ciência-ação, que permite que o processo de seu desenvolvimento realize-se como "uma experimentación rigurosa em situación de trabajo" (idem). Neste procedimento, as ações profissionais seguem a lógica da intervenção de maneira análoga a uma pesquisa científica e abrem a possibilidade de que a razão prática das açôes de atores autônomos no sistema de trabalho permita um "poder comunicativamente generado" pelos assalariados. Com tais capacidades conquistadas, eles dispõem de competências para intervençôes significativas na organização do trabalho, que permitem a articulação e implantação dos seus interesses coletivos e competências transformadoras. 
Aplica-se, neste conceito de Rojas, uma visão integral da essência histórica-crítica das categorias trabalho (Marx) e comunicação (Habermas). Ao assumir o "poder estruturante" (Tanguy), os assalariados associados geraram as competências técnicas, estratégicas e comunicativas para a definição verdadeiramente autônoma da organização do trabalho como "zona de inovação", permitindo a reapropriação subjetiva e coletiva do "conhecimento e da habilidade, das forças produtivas gerais do cérebro social, que foi absorvido pelo capital e aparece, portanto, como qualidade do capital" (Marx, s/n, p. 587).

Cabe-nos, então, a tarefa de definir as competências não somente como necessidade crescente dos novos conceitos de produção, especialmente nos serviços tecnicamente sofisticados (Zarifian, 1995 e 1999), mas também na perspectiva da formação do sujeito: implicando, na reflexão sobre as principais categorias de um conceito dialético de competência, a relação entre trabalho, universalidade, comunicação e sensibilidade. ${ }^{18}$ Entendo assim a dimensão integral-universal de um conceito dialético de competência.

\section{Resumo}

Para Machado,

a noção de competência é, de fato, uma noção forte e deve ser recuperada, mas numa perspectiva que rompa com os critérios que a estão orientando na atualidade: o fatalismo da disputa competitiva (...). Do mundo do trabalho vem o "modelo de competências" com todas as contradiçôes que ele suscita. Vem também a constatação de que ser competente representa, também, saber transgredir. (Machado, 1998, p. 93)

Isto significa, no processo de produção e de serviço, a potencialidade de superar os limites da ocupação/profissão impostos aos assalariados pela lógica da divisão do trabalho capitalista: serem competentes na luta para a realização de estruturas de trabalho qualificantes e participativas. Além das mudanças político-organizacionais das empresas e instituições direcionadas para a cooperação em equipes e redes, que permitem interações de tipo "zona de inovação", os profissionais precisam de capacidades subjetivas, sócio-cooperativas e sócio-comunicativas, para poder agir, autônoma e coletivamente, neste ambiente complexo e conflituoso.

A dimensão psicossocial para o desenvolvimento dessas novas competências pode ter sua orientação conceitual na definição do "eu 
socialmente competente", desenvolvida por Barbara Freitag, ao analisar a recepção da teoria piagetiana por parte de Habermas:

Para Piaget e Habermas a "competência para o discurso" significa justamente a autonomia do "Eu" face aos ditames da sociedade e sua "linguagem autorizada". A "competência para o discurso" do "Eu" autônomo refere-se a uma competência cognitiva, lingüística, moral e interativa do sujeito que atingiu cognitivamente o estágio do pensamento hipotético dedutivo piagetiano; (...) $\mathrm{O}$ "Eu" autônomo e competente é aquele que resiste à coerção da sociedade e dos mais fortes, opondo-se a heteronomia oposta pelo social. (Freitag, 1991, p. 93)

As categorias norteadoras de um conceito de competência deveriam evitar que os conceitos pedagógicos aplicados se tornem uma nova moda pedagógica, ou ajustem somente as capacidades laborais e interaçóes intersubjetivas dos homens à nova ideologia do capital "progressista", mas, ao contrário, contribuam para um entendimento de um conceito de "politecnia", de formação integral do homem, em referência às contribuições de Marx e de Habermas. Entendemos, assim, um conceito crítico-emancipatório de competência através do seu "poder estruturante" para a "transformação" da realidade social.

\section{Recebido em setembro de 2001 e aprovado em maio de 2002.}

\section{Notas}

1. Sobre a discussão na Alemanha, ver Markert, 2000a.

2. Veja: Machado, 1998; Manfredi, 1998; Markert, 2000a e 2000b; Ramos, 2001; Rojas, 1999; UnesCo, 1997; Zarifian, 1999, 2001.

3. Manfredi caracteriza, assim, esta dimensão integral: "Situar e remeter a noção de competência aos contextos, espaços e tempos sócio-culturais significam não só incorporar outras dimensões de análise, mas também procurar estabelecer relações de historicidade entre sujeitos, contextos e tempos" (1998, p. 42).

4. Este conceito foi desenvolvido no Instituto de Göttingen pelos autores Gerst, Schumann et. al., 1995. Veja: Markert, 1998.

5. Veja as contribuições semelhantes em Zarifian, 1999 e 2000; Rojas, 1999.

6. "Uma parte crescente dos contatos e das trocas de conhecimentos que um assalariado mobiliza na sua atividade profissional vem das redes nas quais é inserido, e não só da equipe. Há razôes profundas e evidentes para isso: uma parte crescente dos problemas efetivamente tratados é transversal a diferentes ofícios da empresa" (Zarifian, 2000, p. 23).

7. No Brasil, como ponto de partida para um entendimento integral destas dimensões e a discussão sobre um conceito de competência, vale a referência nas "Diretrizes Curriculares Nacionais para o Ensino Médio" (CEB, 1998). Nestas "Diretrizes", o ensino médio deveria preparar os alunos para o futuro, vinculando "a educação com o mundo do tra- 
balho e a prática social, consolidando a preparação para o exercício da cidadania e propiciando preparação básica para o trabalho" (CEB, 2000, p. 219f).

8. No momento, não podemos entrar num aprofundamento das análises sobre as mudanças no mundo da vida. Quero brevemente resumir que a necessidade de assumir várias ocupações diferentes na sua vida futura abre para as gerações novas, além de um maior "risco social", também a chance de uma auto-realização individual mais satisfatória em contraste com as relaçōes sociais no passado, que foram bem mais restritas (Beck, 1995).

9. Antunes (1999, p. 136) explica neste capítulo seu conceito acerca da "centralidade do trabalho" numa visão ontológica e teleológica, conforme a última obra de Lukács (Ontologia do ser social), e confronta seu entendimento do trabalho com a interpretação de Habermas. Não será possível, neste momento, aprofundar esta discussão. Colocaremos algumas dúvidas sobre a ontologia do trabalho, objetivando justificar a referência para definir outras categorias centrais para um conceito dialético de "competência".

10. Certamente, seria bastante difícil encontrar na obra de Marx tais passagens que reduzem a dialética entre as categorias numa relação esquemática. Refiro-me, nesta anotação, a uma passagem nos "Fundamentos (Grundrisse) da Crítica da Economia Política": "O resultado, no qual nos chegamos, não é que produção, distribuição, intercâmbio, consumação são idênticas, mas que elas formam todas partes de uma totalidade, todas diferentes dentro de uma unidade. A produção estende-se, tanto sobre si mesma na determinação antagônica da produção, bem como sobre os outros momentos. (...) Contudo, a produção, na sua forma específica, é por sua vez determinada por outros momentos" (Marx, s/ d, p. 20). Vejo, nesta passagem, uma compreensão não esquemática, mas dialética entre produção e intercâmbio (Verkehrsformen - noção, que inclua em alemão a dimensão econômica e sócio-comunicativa).

11. Marx continua: "Pois não são apenas os cinco sentidos, mas igualmente os chamados sentidos espirituais, os sentidos práticos (desejar, amar etc.), em suma, a sensibilidade humana e o caráter humano dos sentidos, que só podem vingar através da existência de seu objeto, através da natureza humanizada".

12. Marx escreve sobre a relação da arte grega à época atual: "Mas a dificuldade não reside em compreender que a arte e a epopéia grega são vinculadas a certas formas do desenvolvimento social. A dificuldade é porque eles oferecem-nos ainda um prazer estético e valem para nós, certa maneira, como norma e padrão inacessível. (...) Mas, porque a infância da humanidade não deveria assumir um estímulo eterno, mesmo que seu estágio nunca mais volte?” (Grundrisse, s/a, p. 31).

13. "O homem rico é, ao mesmo tempo, aquele que precisa de um complexo de manifestações humanas da vida, e cuja própria auto-realização existe como uma necessidade interior" (Marx, 1983, p. 125).

14. "O desenvolvimento livre da individualidade, e por isto não a redução do tempo de trabalho necessário para realizar o trabalho surplus, mas principalmente a redução do trabalho necessário da sociedade para um mínimo, qual corresponde a formação artística, científica dos homens etc., em conseqüência do tempo livre e dos meios dispostos para todos (...). O capital é a contradição processual na maneira que reduz o tempo do trabalho para um mínimo, mas precisa em contrapartida o tempo do trabalho como única fonte da riqueza" (Marx, s/a, p. 593). Como trabalho, então, poderia ser entendida como categoria ontológica e teleológica da libertação da humanidade, enquanto a liberdade verdadeira dos homens se desenvolve essencialmente acima do trabalho, no tempo livre?

15. "Outra vez, se na sociedade, como ela é, as condições materiais de produção e as relações correspondentes de intercâmbio (econômico e social-comunicativo, W.M.) não fossem existentes numa maneira ainda oculta, todas as tentativas explosivas seriam donquichotanias" (Marx, s/a, p. 77). 
16. Um conceito pedagógico-didático adequado de estruturas de trabalho qualificante parece ser a "ilha de aprendizagem", desenvolvida e aplicada em várias empresas na Alemanha. Neste modelo pedagógico-produtivo encontra-se uma excelente preparação para a execução das competências requeridas em equipes no sentido de "ilha de produção". Neste momento, não é possível aprofundar esta informação (ver: Markert, 2000b).

17. “El método de la 'zona de innovación' se completa al tener en cuenta la dinámica de la interacción entre sujeto de experiencia e interlocutor significativo. Se trata de cinco puntos, referidos a: 1) la identificación precisa de la possibilidad de innovación; 2) las construcciones del transfondo en que se forma; 3) la dinámica da interacción; 4) los métodos de relexión cognitiva grupal que permiten organizarla en al empresa y 5) los dispositivos que permiten desarrallola como una 'creación organizacional' de saber" (Rojas, 1999, p. 21).

18. Veja: Markert, 2001. Naquele trabalho refiro-me à dimensão da "Estética da Sensibilidade" como um dos princípios centrais de Ensino Médio (CEB, 2000, p. 220). Habermas integra a "educação estética do homem" no seu conceito filosófico de modernidade (2000, p. 66 e ss.). Neste sentido, proponho a inclusão da categoria "sensibilidade" num conceito integral de competência.

\section{Referências bibliográficas}

ANTUNES, R. Os sentidos do trabalho. São Paulo: Boitempo, 1999.

BAETHGE, Martin. "Trabalho, socialização, identidade: A crescente subjetivação normativa do trabalho". In: MARKERT, W. (Org.), Teorias de Educação do Iluminismo, conceitos de trabalho e do sujeito, Rio de Janeiro: Tempo Brasileiro, 1994.

BAETHGE, M.; SCHIERSMANN, C. Prozeßorentierte Weiterbildung - Perspektiven und Probleme eines neuen Paradigma der Kompetenzentwicklung für die Arbeitswelt der Zukunft. In: Kompetenzentwicklung, 1998. Forschungsstand und Forschungsperspektiven (Educação contínua - Perspectivas e problemas do novo paradigma do desenvolvimento de competências para o mundo do trabalho no futuro. In: Desenvolvimento de competência, 1998. Situação e perspectivas para pesquisas). New York/Berlin/Münster/ München: Waxman, 1998.

BASTOS, J.A. Educação tecnológica - Conceitos, características e perspectivas. Tecnologia \& Educação, Curitiba: CeFet-PR, 1998.

BECK, U. Risikogesellschaft - Auf dem Weg in eine andere Moderne (Sociedade de Risco - no caminho para uma outra modernidade). Fankfurt: Suhrkamp,1995.

CÂMARA da Educação Básica, Resolução CEB, nº 3, 26 de junho de 1998. 
DIRETRIZES Curriculares Nacionais para o Ensino Médio. Educação \& Sociedade, Campinas: CEDES, 2000, no 70.

GERST et al. Gruppenarbeit in den 90ern: Zwischen strukturkonservativer und strukturinnovativer Gestaltungsvariante (Trabalho em grupo nos anos 90: Entre um modelo conservador e inovador). Göttingen: Sofi (Instituto de Pesquisa de Ciências Sociais), 1995.

HABERMAS, J. "Trabalho e interação e técnica e ciência como ideologia". In: Habermas, J., Técnica e Ciência como "Ideologia". Lisboa: Ediçôes 70, 1987.

"O materialismo histórico e o desenvolvimento de estruturas normativas". In: Habermas, J., Para a reconstrução do materialismo histórico, São Paulo: Brasiliense, 1990.

. "Individuierung durch Vergesellschaftung" ("Individualização através da socialização"). In: BecK, U.; Beck-Gernsheim, E. (Orgs.), Riskante Freiheiten (Liberdades arriscadas), Frankfurt: Suhrkamp, 1994.

. O discurso filosófico da modernidade. São Paulo: Martins Fontes, 2000.

LUKÁCS, G. Os princípios ontológicos fundamentais de Marx. São Paulo: Ciências Humanas, 1979.

MACHADO, L. O "modelo" de competências e a regulamentação da base curricular nacional e de organização do ensino médio. Trabalho \& Educação, Universidade Federal de Minas Gerais: NeTE, 1998, no 4.

MANACORDA, M. Marx e a pedagogia moderna. São Paulo: Cortez, 1991.

MANFREDI, Sílvia M. Trabalho, qualificação e competência profissional - Das dimensões conceituais e políticas. Educação \& Sociedade, Campinas: Papirus, 1998, nº 64.

MARKERT, W. "Novas formas de trabalho e de cooperação na empresa”. In: MARKerT, W. (Org.), Teorias de educação do Iluminismo, conceitos de trabalho e doSujeito, Rio de Janeiro: Tempo Brasileiro, 1994.

. (Org.). Trabalho, qualificação e politecnia. Campinas: Cedes, 1996 a.

. "Trabalho e comunicação em Marx e Habermas”. In: PAIVA, V. (Org.), Atualidade de Escola de Frankfurt, Contemporaneidade \& Educação, Rio de Janeiro, 1996b. 
. "Lean Production - Uma revolução da forma de produção capitalista? Discussão alemã e internacional, sua implantação no Brasil e conseqüências para a formação profissional". In: MARKERT, W. (Org.), Formação profissional no Brasil: Reflexões teóricas e análises da sua práxis, Rio de Janeiro: Ediçôes Paratodos, 1997.

- Trabalho em grupo nas empresas alemãs: Um novo modelo de produção e uma proposta de formação profissional. Educação \& Sociedade, Campinas: Cedes, 1998, no 64.

Novos paradigmas do conhecimento e modernos conceitos de produção - Implicações para uma nova didática na formação profissional. Educação \& Sociedade, Campinas: CEDEs, 2000a, no 72 .

- "O conceito da ilha de aprendizagem na fábrica montadora de veículos Daimler Benz em Wörth - Um estudo de caso". In: Transformaçōes no Trabalho e Impactos na Educação Profissional, Rio de Janeiro/Brasília: CIET/SENAI, 2000b.

- Trabalho, universalidade, comunicação e sensibildade - Aspectos teórico-metodológicos para um conceito dialético de Competência. Trabalho para o GT 9 na 24a Reunião da AnPED, 2001.

MARX, K. Manuscritos econômicos e filosóficos. In: Fromm, E. (Org.), Conceito marxista do homem, Rio de Janeiro: Zahar, 1983.

1988.

. O Capital. $3^{\text {a }}$ ed. (Cap. XIII, vol. I), São Paulo: Nova Cultural,

. Grundrisse der politischen Ökonomie (1857/58) (Fundamentos da crítica da economia política). Frankfurt: Europäische Verlagsanstalt (versão: Moscou, 1939).

MARX, K.; ENGELS, F. Textos sobre educação e ensino. São Paulo: Moraes, 1985 .

. A ideologia alemã. São Paulo: Hucitec, 1991.

PAIVA, V. O mundo em mudança: Deslocamento temático no final do século e convivência com a incerteza. Contemporaneidade \& Educação, Rio de Janeiro, 1999, no 6.

RAMOS, M. A pedagogia de competências. São Paulo: Cortez, 2001. 
ROPÉ, F.; TANGUY, L. Saberes e competências. Campinas: Papirus, 1997.

ROJAS, Eduardo. El saber obrero y la innovación en la empresa. Montevideo: CinTERFor, 1999.

TOURAINE, A. Crítica da modernidade. Petrópolis: Vozes, 1994.

UNESCO. Educação - Um tesouro a descobrir. Relatório para a Unesco da Comissão Internacional sobre Educação para o Século XXI. Porto: AsA, 1996.

ZARIFIAN, P. Travail e comunication. Paris: PUF, 1996.

ZARAFIAN, P. El modelo de competência y los sistemas productivos. Montevideo: Cinterfor, 1999. . Objetivo competência. São Paulo: Atlas, 2001. 